\title{
VARIABILITY OF ISOZYME AND RAPD MARKERS AMONG ISOLATES OF MUCOR GENEVENSIS*
}

\author{
Cs. VÁgVÖlgyi, ${ }^{1 * *}$ Zs. Kasza, ${ }^{1}$ Ildikó Nyilasi, ${ }^{1}$ KlÁRA Ács ${ }^{1}$ and T. PAPP ${ }^{2}$ \\ ${ }^{1}$ Department of Microbiology, Faculty of Sciences, University of Szeged, Hungary \\ ${ }^{2}$ Department of Microbiology, Faculty of Sciences, HAS Microbiological Research Group, \\ University of Szeged, Szeged, Hungary
}

(Received: August 31, 2000; accepted: October 5, 2000)

\begin{abstract}
Mucor genevensis is a dimorphic and homothallic fungal species (Zygomycetes). Ten M. genevensis strains, each strain of the recently described new homothallic species (M. meguroense and M. hachijyoensis) and strains of $M$. hiemalis and M. piriformis (as outgroups for numerical analysis) were investigated. Five different enzyme systems (CAT, GDH, G6D, MDH and SOD) and five 10-bp random primers were used in isoenzyme and random amplified polymorphic DNA analyses, respectively. The data from these studies were subjected to numerical analyses. Substantial intraspecific variability was detected in M. genevensis with both of the methods applied. Though both the M. meguroense strain and the M. hachijyoensis strain revealed characteristic differences, they grouped closer to the homothallic M. genevensis than to the heterothallic $M$. piriformis and M. hiemalis strains.
\end{abstract}

Keywords: Genetic variability - homothallism - isoenzyme analysis - Mucor genevensis - RAPD analysis

\section{INTRODUCTION}

The species Mucor genevensis is of interest as concerns both its dimorphism and its homothallism. The latter feature is rather rare among fungi belonging in the genus Mucor, where most of the known species are heterothallic. The comprehensive taxonomic work of Schipper [13] listed only 4 homothallic species (M. azygosporus, $M$. bacilliformis, M. bainieri and M. genevensis). There are a few other descriptions of homothallic Mucor species, but with a somewhat uncertain taxonomic status, e.g. $M$. philippovi [9] and M. parvisporus [6]. These doubtful taxa are generally represented by a single isolate. This list of homothallic Mucor species was recently extended with 2 new species (M. meguroense and M. hachijyoensis [19]), on the basis of the morphological and physiological traits observed for 2 Mucor isolates collected in Japan.

The investigation of micro- and macromorphological characteristics comprises the classical basis for strain identification and species delimitation in fungal taxonomy. However, with the significance of conventional strain typing left partially untouched,

\footnotetext{
*Dedicated to Professor Lajos Ferenczy on the occasion of his 70th birthday.

**Corresponding author; e-mail: csaba@bio.u-szeged.hu
} 
different molecular methods have gained widespread application and special importance both alone and as part of integrated approaches in fungal systematics. The main advantage of different molecular markers is that they allow the detection of practically unlimited numbers of independent polymorphic genetic loci. As well-established methods, isoenzyme analysis and random amplification of polymorphic DNA (RAPD) analysis are useful for providing genetic markers for investigations of genetic polymorphism, and have also proved to be valuable tools in the handling of certain taxonomic questions in the genus Mucor and related genera [10, 16-18].

In the present study, the applicability of these approaches for elucidation of the intraspecific variability of M. genevensis (the most ubiquituous homothallic Mucor species) and its taxonomic relationship to the recently described homothallic Mucor species (M. meguroense and M. hachijyoensis) was investigated.

\section{MATERIALS AND METHODS}

\section{Fungal strains and cultivation}

The names and origins of the fungal strains used in this study are given in Table 1. Mycelia were grown in $150 \mathrm{ml}$ of yeast extract-glucose (1\% glucose, $0.5 \%$ yeast extract and $1 \% \mathrm{KH}_{2} \mathrm{PO}_{4}$ ) or potato-dextrose liquid medium for DNA or protein extraction, respectively. After culturing at $37^{\circ} \mathrm{C}$ on a rotary shaker at $200 \mathrm{rpm}$ for 3 days, mycelia were harvested by filtration and stored at $-70{ }^{\circ} \mathrm{C}$ until use.

\section{Isoenzyme analysis}

The preparation of protein extract and gel electrophoresis were performed essentially as described earlier [16]. The enzyme systems used were catalase (CAT, EC 1.11.1.6 [21]), glutamate dehydrogenase (GDH, EC 1.4.1.4 [1]), glucose-6-phosphate dehydrogenase (G6D, EC 1.1.1.49 [8]), malate dehydrogenase (MDH, EC 1.1.1.38 [3]) and superoxide dismutase (SOD, EC 1.15.1.1 [2]). After incubation at $21{ }^{\circ} \mathrm{C}$ (in the dark), the gels were rinsed, first in distilled water, and next in $7 \%$ acetic acid, and then read.

\section{RAPD analysis}

DNA was extracted by using a variation of the rapid lithium chloride procedure [7]. Pieces of frozen mycelia $(0.5 \mathrm{~g})$ were powdered with liquid nitrogen, transferred immediately into a sterile Eppendorf tube and mixed with $0.5 \mathrm{ml}$ of ice-cold LETS buffer (0.1 M LiCl, $10 \mathrm{mM}$ EDTA, $10 \mathrm{mM}$ Tris/HCl, $\mathrm{pH}$ 8.0, 0.5\% SDS). The mixture was vortexed until a fine mycelial slurry was obtained, which was quickly frozen by immersion in liquid nitrogen. The tube was transferred into a water bath at $65^{\circ} \mathrm{C}$ 
Table 1

Fungal strains investigated in the present study.

\begin{tabular}{|c|c|c|}
\hline Species name & Original code & Source \\
\hline M. genevensis & NRRL 1411 & u.s. \\
\hline M. genevensis & NRRL 1821 & u.s., Wisconsin, USA \\
\hline M. genevensis & NRRL 1410 & u.s. \\
\hline M. genevensis & NRRL 1412 & u.s. \\
\hline M. genevensis & MUFS 038 & leaf litter, Knysna forest, South Africa \\
\hline M. genevensis & NRRL 1407 & u.s. \\
\hline M. genevensis & NRRL 1755 & u.s. \\
\hline M. genevensis & NRRL 1758 & u.s., Wisconsin, USA \\
\hline M. genevensis & NRRL 1756 & u.s. \\
\hline M. genevensis & NRRL 1408 & u.s. \\
\hline M. hachijyoensis & FFPRI TW70-1179 & soil, Hachijo-jima, Japan \\
\hline M. meguroense & FFPRI TW92-268 & $\begin{array}{c}\text { leaves of Phellodendron amurense, } \\
\text { Meguro, Tokyo, Japan }\end{array}$ \\
\hline M. hiemalis $f$. hiemalis & WRL CN(M) 328 & soil, Halfield College, UK \\
\hline M. hiemalis $f$. luteus & NRRL 3632 & u.s., Germany \\
\hline M. piriformis & 17-C-1 & Persimmon, California, USA \\
\hline
\end{tabular}

u.s. = unknown source

*Abbreviations: NRRL, Agricultural Research Service C. C., Peoria, Illinois, USA; WRL, Wellcome Bacterial Collection, Beckenham, UK; FFPRI, Herbarium, Forestry and Forest Product Research Institute, Tsukuba, Japan; MUFS, Department of Microbiology and Biochemistry, Orange Free State, South Africa.

for few minutes, $0.2 \mathrm{ml}$ of $10 \%$ SDS was added and the mixture was vortexed. The slurry was extracted once with phenol : chloroform $(25: 24)$, then with phenol, and next again with the phenol : chloroform $(25: 24)$ mixture. Finally, the sample was extracted with an equal volume of a chloroform : isoamyl alcohol $(24: 1)$ mixture. DNA was precipitated from the aqeuous phase with two volumes of ethanol at -20 ${ }^{\circ} \mathrm{C}$. After centrifugation $(15 \mathrm{~min}$ at $10000 \mathrm{~g})$, the resulting pellet was dried under vacuum, and resuspended in $30 \mu \mathrm{l}$ of TE buffer.

Amplification of template DNA was carried out as described by Williams et al. [20] with slight modifications. Each $25 \mu 1$ of reaction mixture contained $2.5 \mu 1$ of $10 \times$ PCR buffer, $200 \mu \mathrm{M}$ each of dATP, dCTP, dGTP and dTTP (Pharmacia), $2.5 \mathrm{mM}$ $\mathrm{MgCl}_{2}, 0.2 \mu \mathrm{M}$ primer (Random primer kit C, Operon Technologies), $0.5 \mathrm{U}$ of Taq DNA polymerase (Zenon), $2.5 \mu \mathrm{l}$ of genomic DNA extract $(50 \mathrm{ng} / \mu \mathrm{l})$ and sterile distilled water. Sterile mineral oil ( $40 \mu \mathrm{l}$, Sigma) was used as overlay. Control reactions contained all reagents except genomic DNA extract.

Amplifications were performed in a PTC-100-60 DNA thermocycler (MJ Research) programmed for a denaturation step at $94{ }^{\circ} \mathrm{C}$ for $2 \mathrm{~min}$, followed by 1 cycle at $38{ }^{\circ} \mathrm{C}$ for $1 \mathrm{~min}$ and $72{ }^{\circ} \mathrm{C}$ for $2 \mathrm{~min}$, and then 36 cycles at $93{ }^{\circ} \mathrm{C}$ for $1 \mathrm{~min}, 38^{\circ} \mathrm{C}$ for $1 \mathrm{~min}$ and $72{ }^{\circ} \mathrm{C}$ for $2 \mathrm{~min}$. The final cycle concluded with an extension step at $72{ }^{\circ} \mathrm{C}$ for $10 \mathrm{~min}$. DNA from each isolate was amplified with five different 10 -base primers in three separate experiments. The arbitrary primers used were OPC-01 
(TTCGAGCCAG), OPC-02 (GTGAGGCGTC), OPC-04 (CCGCATGTAC), OPC07 (GTCCCGACGA) and OPC-13 (AAGCCTCGTC).

Ten $\mu \mathrm{l}$ of each amplification product was separated by electrophoresis on $1.0 \%$ agarose/TBE (90 mM Tris/borate, $\mathrm{pH}$ 8.0, $2 \mathrm{mM}$ EDTA) gels and visualized by UV fluorescence after ethidium bromide $(0.5 \mu \mathrm{g} / \mathrm{ml})$ staining, using HindIII- and HindIII-EcoRI-digested $\lambda$ DNA as size standards.

\section{Numerical analysis}

From the isoenzyme and RAPD data, matrices based on the presence or absence of a given activity band or an amplification product were created. Jaccard coefficients $\left(\mathrm{S}_{\mathrm{J}}\right)$ were calculated and a dendrogram was produced with a UPGMA (unweighted pair-group method using arithmetic averages [15]) linkage. Computations were performed with the SYNTAX 5.0 software package [11].

\section{RESULTS}

All the enzyme systems investigated revealed some polymorphism among the fungal strains studied (results not shown). The highest variability was found for CAT; 6 different electrophoretic patterns (electromorphs) were detected, while for G6D (Fig. 1) and MDH 4 electromorphs were found. The least variation was observed when the GDH and SOD (Fig. 1) activity stains were used: each indicated 3 different electromorphs.

When all the isoenzymes were taken into account, a definite intraspecific variability was found in $M$. genevensis; the $10 \mathrm{M}$. genevensis strains revealed 6 different electrophoretic phenotypes (EPs). The differences between these EPs were in some cases substantial; some of them exhibited different activity patterns in 3 of the 5 enzyme systems investigated. When a dendogram was created from the isoenzyme data (Fig. 2), all the homothallic Mucor strains clustered together (cluster A) and differed substantially $(\mathrm{D} \geq 0.84)$ from 2 heterothallic Mucor strains (17-C-1 and WRL $\mathrm{CN}(\mathrm{M})$ 328). However, strain NRRL 3632 (which is a heterothallic M. hiemalis $f$. luteus) surprisingly grouped together with the homothallic isolates (cluster $\mathrm{A} / 2$ ). While the isolate M. hachijyoensis remained unclustered, the M. meguroense isolate grouped together with a South African M. genevensis strain (cluster B).

To provide further characters of distinctive value, RAPD analysis of the isolates was carried out. Reproducible amplifications were obtained with all 5 primers tested (results not shown); the number of amplified bands varied between 1 and 17.

All the primers tested revealed high DNA polymorphism among the Mucor isolates. As a result of this, the amplification patterns from the 5 primers together provide a strain-specific characterization (Fig. 3).

A total of 190 RAPD markers were generated from the DNA of the 15 fungal strains investigated. A matrix was calculated from the binary scores of these charac- 


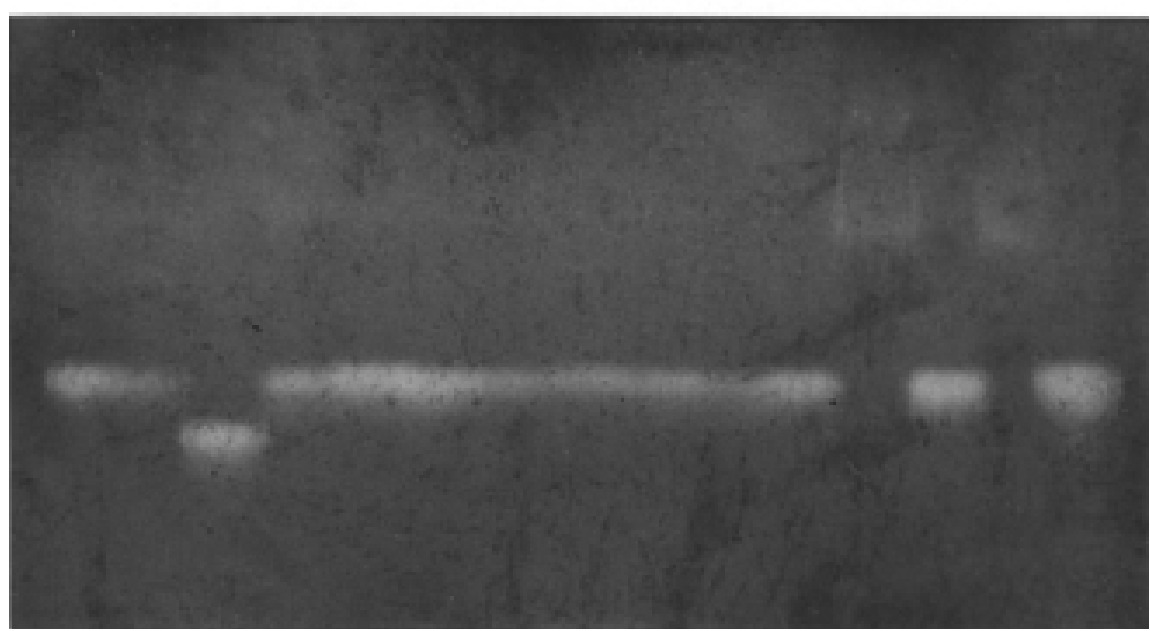

Fig. 1. SOD activity patterns of the Mucor strains. Lanes 1-14: strains NRRL 1407, NRRL 1408, TW701179, NRRL 1410, NRRL 1411, NRRL 1412, NRRL 1756, NRRL 1758, NRRL 1821, MUFS 038, WRL CN(M)328, TW92-268, NRRL 3632 and NRRL 1755, respectively

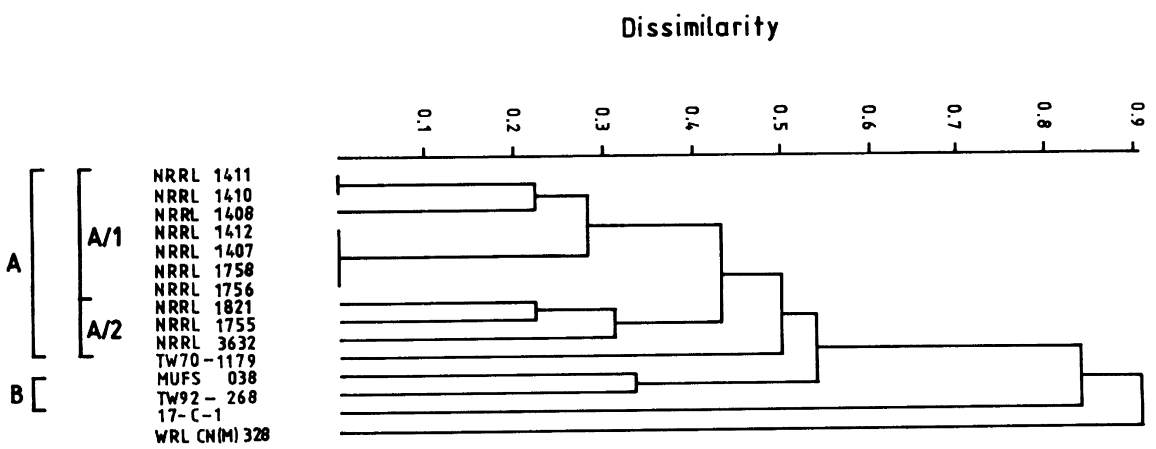

Fig. 2. UPGMA dendrogram produced from isoenzyme analyses of the Mucor strains. The scale represents dissimilarity (squared distance)

ters and a dendrogram was generated by means of the UPGMA clustering (Fig. 4). Fifteen composite amplification types were identified for Mucor isolates, indicating a higher degree of variability than found in isoenzyme studies. Although this dendogram is more complex than that created from the isoenzyme data, it also reveals the above-mentioned clustering of the homothallic strains. 


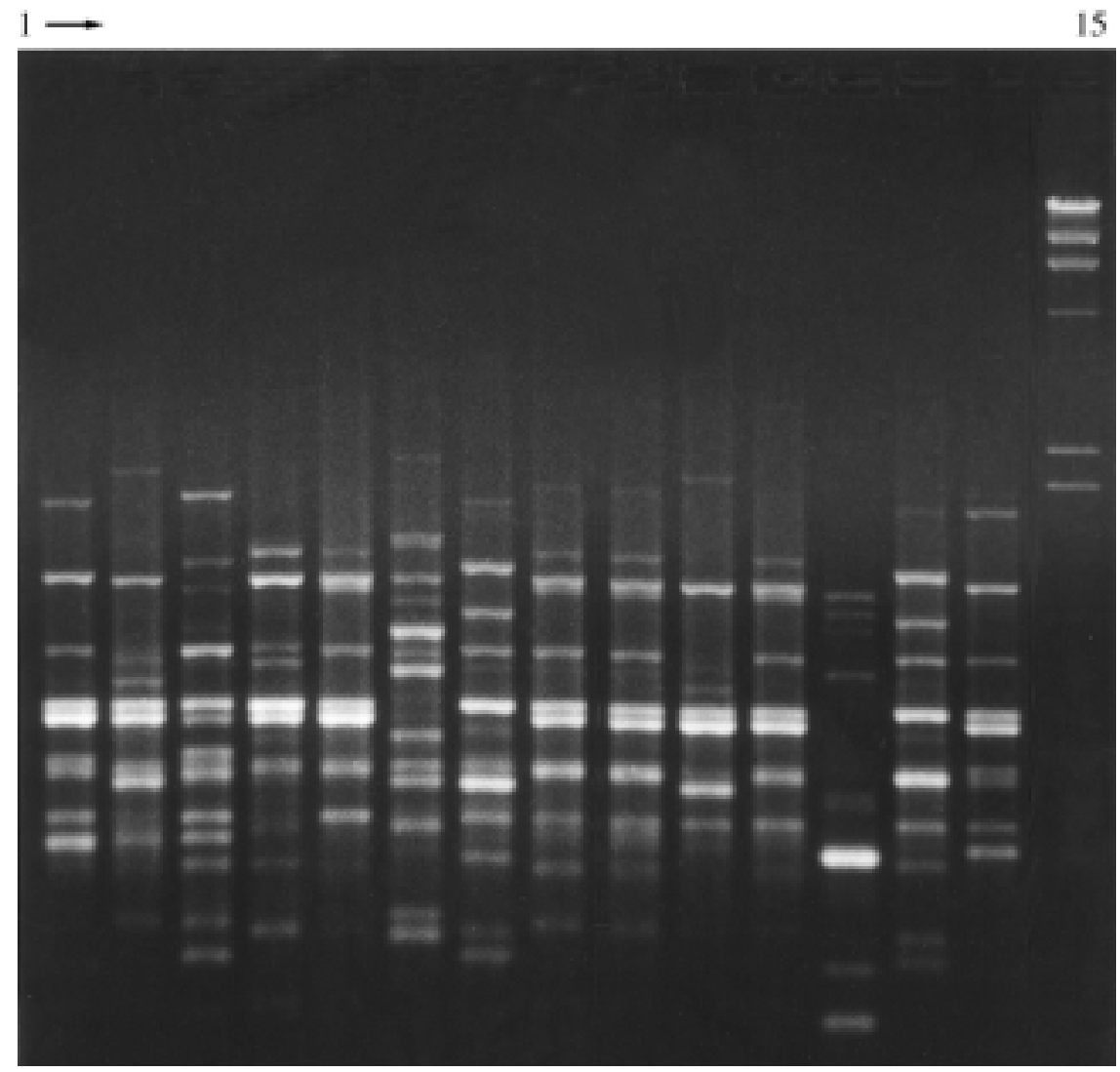

Fig. 3. Amplification products of Mucor DNA with primer OPC-13. Lanes 1-14: strains NRRL 1411, NRRL 1821, TW70-1179, NRRL 1410, NRRL 1412, NRRL 3632, MUFS 038, NRRL 1407, NRRL 1755, NRRL 1758, NRRL 1756, WRL CN(M)328, TW92-268 and NRRL 1408, respectively. Lane 15: HindIII-digested $\lambda$ DNA as size standard

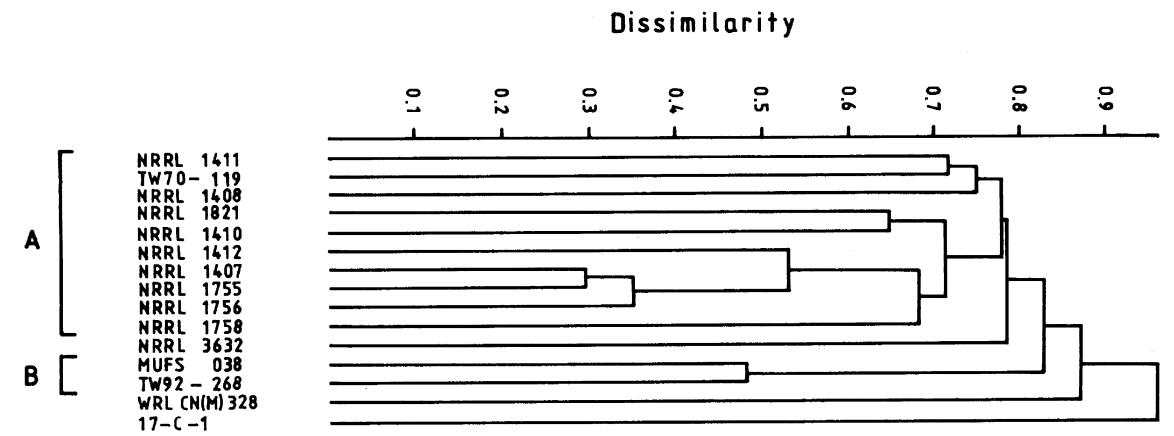

Fig. 4. UPGMA dendrogram produced from RAPD analyses of the Mucor strains. The scale represents dissimilarity (squared distance) 


\section{DISCUSSION}

The members of the genus Mucor have few and even variable morphological characters; strains of a single species may vary in their cultural characteristics (macromorphology), and to a lesser degree in their micromorphologies. This has a serious impact on the precision of species identification on a morphological basis, and leads in several cases to ambiguity when new isolates have to be identified.

Inclusion of a mating study evidently does not simplify this scheme. The mating behaviour of the heterothallic Mucor species could be rather complex [14]: some heterothallic strains react either as $(+)$ or as $(-)$ strains; some have lost their mating potencies (neutral strains); zygospore production in various matings under the same conditions with one common partner may differ greatly due to unknown physiological factors; and azygospores could be formed or in intraspecific and interspecific crosses, and even apparently normal zygospores could be produced between strains of different species (e.g. M. indicus and M. variosporus [13]).

Mating studies are evidently of no use when homothallic Mucor isolates have to be identified. Though abundantly produced zygospores could be good sources of additional morphological characters, their proper evaluation is no less problematic as than that of the vegetative structures. Homothallic strains are rather rare in the genus Mucor and, partly in consequence of the above-mentioned reasons, both the number of accepted homothallic species and their taxonomic status have long remained subjects of debate.

Hesseltine [5] included M. genevensis in the section Genevensis, together with 3 other homothallic species. Schipper [13] also accepted 4 homothallic species, but she emphasized their connections to different heterothallic species: M. genevensis was handled as a counterpart of the heterothallic M. hiemalis.

The results of our experiments revealed a rather high genetic polymorphism in the species M. genevensis. In the case of Rhizomucor miehei, another homothallic zygomycetes, the intraspecific genetic polymorphism was found to be low [18]. For example, there was no polymorphism in the 26 isoenzyme markers determined. As the heterothallic Rhizomucor pusillus revealed much higher genetic variability in the same study, the different sexual strategies were presumed to be responsible for the very different levels of the intraspecific polymorphisms of these two closely related species. Interestingly, the high genetic variability of $M$. genevensis does not fit into this scheme. Unfortunately, homothallic Mucor isolates are rather rare (several species are represented by only a single or very few isolates), and it is therefore difficult to decide whether this is a general phenomenon of mesophilic homothallic Mucor species.

Among the taxonomic deductions that could be drawn from our results, the most important is that the single isolates of M. meguroense and M. hachijyoensis seem to represent separate species: on the basis of the molecular markers investigated, the latter clearly displays a greater similarity to $M$. genevensis. Surprisingly, the $2 M$. hiemalis strains involved in this study as outgroups were found to be very different: the strain representing $M$. hiemalis $f$. luteus (NRRL 3632) displayed a rather close 
connection to the homothallic Mucor strains, while the strain representing $M$. hiemalis $f$. hiemalis (as the other heterothallic Mucor strain) was clearly separated from homothallic isolates. This problem could not be solved from the present study, as it requires a more detailed investigation of the intraspecific genetic polymorphism of $M$. hiemalis. From this point of view, it is worth while to mention the investigation of Havens [4] carried out in the section Hiemalis of the genus Mucor: mating tests were coupled with isoenzyme analysis to reduce the possibility of misidentifications. The investigated "species" exhibited a relatively high polymorphism; the isozyme similarity and sexual compatibility displayed a correlation coefficient of only 0.61 .

As both dendograms, based on independently created data matrices from different molecular methods, show the high similarity of the M. meguroense isolate with a South African homothallic Mucor isolate (obtained as M. genevensis MUFS 038), they might be handled as representatives of the same homothallic Mucor species.

This study again demonstrates the merits of the use of different molecular markers in resolving taxonomic problems of fungal taxa when the investigation of morphological traits does not supply sufficient solid information.

\section{ACKNOWLEDGEMENTS}

This study was supported in part by a Hungarian Scientific Research Fund (OTKA) grant, No. 032738. We thank K. O'Donnell, T. Watanabe, T. J. Michailides, C. Pohl and A. Botha for providing us with fungal isolates.

\section{REFERENCES}

1. Anné, J., Peberdy, J. F. (1981) Characterisation of interspecific hybrids between Penicillium chrysogenum and P. roqueforti by iso-enzyme analysis. Trans. Br. Mycol. Soc. 77, 401-408.

2. Beauchamp, C., Fridovich, J. (1971) Superoxide dismutase: improved assays and an assay applicable to acrylamide gels. Anal. Biochem. 44, 276-287.

3. Brewer, G. J., Sing, C. F. (1970) An introduction to isozyme techniques. Academic Press, New York.

4. Havens, P. L. (1976) Comparative zone electrophoresis and mating experiments in the taxonomy of Mucor hiemalis. Mycotaxon 4, 218-232.

5. Hesseltine, C. W. (1954) The section Genevensis of the genus Mucor. Mycologia 46, 358-366.

6. Kanouse, B. B. (1924) The life history of a new homothallic Mucor. Pap. Mich. Acad. Sci. 3, $120-130$.

7. Leach, J., Finkelstein, D. B., Rambosek, J. A. (1986) Rapid miniprep of DNA from filamentous fungi. Fungal Genet. Newslett. 33, 32-33.

8. Mulvey, M., Vrijenhoek, R. C. (1981) Genetic variation among laboratory strains of the planorbid snail Biomphalaria glabrata. Biochem. Genet. 19, 1169-1182.

9. Naumov, N. A. (1935) Opredelitel Mukorovych (Mucorales). 2nd revised ed. Bot. Inst. Acad. Sci. USSR, Moscow and Leningrad. 140 pp. (In Russian).

10. Papp, T., Vágvölgyi, Cs., Kerényi, Z., Nagy, Á., Michailides, T. J. (1997) DNA amplification polymorphisms of Mucor piriformis. Ant. Leeuwenhoek 72, 167-173.

11. Podani, J. (1993) SYN-TAX-pc, Computer programs for multivariate data analysis in ecology and systematics. Version 5.0. User's Guide. Scientia Publishing, Budapest.

12. Schipper, M. A. A. (1973) A study on variability in Mucor hiemalis and related species. Stud. Mycol. 4, $1-40$. 
13. Schipper, M. A. A. (1978) On certain species of Mucor with a key to all accepted species. Stud. Mycol. 17, 1-52.

14. Schipper, M. A. A. (1986) Mating ability and the species concept of the Zygomycetes. In: Rayner, A. D. M., Brasier, C. M., Moore, D. (eds) Evolutionary Biology of Fungi. Cambridge Univ. Press, pp. 261-269.

15. Sneath, P. H. A., Sokal, R. R. (1973) Numerical taxonomy. W. H. Freeman and Co., San Francisco.

16. Vágvölgyi, Cs., Papp, T., Palágyi, Zs., Michailides, T. J. (1996) Isozyme variation among isolates of Mucor piriformis. Mycologia 88, 602-607.

17. Vágvölgyi, Cs., Vastag, M., Ács, K., Papp, T. (1999) Rhizomucor tauricus: a questionable species of the genus. Mycol. Res. 103, 612-618.

18. Vastag, M., Papp, T., Kasza, Zs., Vágvölgyi, Cs. (1998) Differentiation of Rhizomucor species by means of carbon source utilization and isoenzyme analysis. J. Clin. Microbiol. 36, 2153-2156.

19. Watanabe, T. (1994) Two new species of homothallic Mucor in Japan. Mycologia 86, 691-695.

20. Williams, J. G. K., Kubelik, A. R., Rafalski, J. A., Tingey, S. V. (1991) Genetic analysis with RAPD markers. In: Bennett, J. W., Lasure, L. L. (eds) More genetic manipulations in fungi. Academic Press, San Diego. pp. 431-439.

21. Woodbury, W., Spencer, A. K., Stanmann, M. A. (1971) An improved procedure using ferricyanide for detecting catalase isozymes. Anal. Biochem. 44, 301-305. 
